\title{
OS ANOS 1980 E AS AVALIAÇÕES EM LARGA ESCALA COMO FENÔMENO HISTÓRICO
}

\author{
Los años 1980 y las evaluaciones en larga escala como fenómeno histórico
}

The 1980 s and Large-Scale Evaluations as a Historical Phenomenon

\author{
Rosimar Serena Siqueira Esquinsani \\ rosimaresquinsani@upf.br \\ Conselho Nacional de Desenvolvimento Científico e Tecnológico / CNPq. Brasil
}

Fecha de recepción: 01/03/2019

Fecha de aceptación: 18/05/2019

Resumo: Atualmente, as avaliações em larga escala constituem-se em uma das ações mais efetivas na definição dos rumos da educação no Brasil. Mas, qual o cenário histórico de surgimento das avaliações em larga escala e quais as implicações de tal cenário para o fortalecimento dessas avaliações? Como tal ação chegou a consubstanciar-se em diretriz política na atualidade? A partir de uma pesquisa bibliográfica pautada por metodologia analítico-reconstrutiva, o texto assume que as avaliações em larga escala brotam como fenômenos datados e históricos especialmente a partir dos anos 1980. Neste sentido, objetiva discutir circunstancial e historicamente os anos 1980 como cenário de preparação para as reformas dos anos 1990 que incluíram também o surgimento das avaliações em larga escala, tangenciando dois posicionamentos: a) as avaliações em larga escala como agenda internacional que materializaram, no campo das políticas educacionais, uma tendência ideológica referenciada e fortalecida na instalação e ampliação do Estado avaliador, e b) as avaliações em larga escala como uma contingência da realidade educacional vigente. Como conclusão, assume-se que o contexto histórico dos anos 1980 representou, por um lado, a sustentação ideológica para as avaliações referidas e, por outro lado, promoveu a justificativa social para os emergentes mecanismos de avaliação em larga escala.

Palavras-chave: avaliação em larga escala; política educacional; contexto dos anos 1980.

Resumen: Actualmente, las evaluaciones a gran escala se constituyen en una de las acciones más efectivas en la definición de los rumbos de la educación en Brasil. Pero, ¿cuál es el escenario histórico de surgimiento de las evaluaciones a gran escala y cuáles las implicaciones de tal escenario para el fortalecimiento de esas evaluaciones? ¿Cómo tal acción llegó a consubstanciarse en directriz 
política en la actualidad? A partir de una investigación bibliográfica pautada por metodología analíticoreconstructiva, el texto asume que las evaluaciones a gran escala brotan como fenómenos datados e históricos especialmente a partir de los años 1980. En este sentido, objetiva discutir circunstancial e históricamente los años 1980 como escenario de preparación para las reformas de los años 1990 que incluyeron también el surgimiento de las evaluaciones a gran escala, tangenciando dos ubicaciones: a) las evaluaciones a gran escala como agenda internacional que materializaron, en el campo de las políticas educativas, una tendencia ideológica referenciada y fortalecida en la instalación y ampliación del Estado evaluador, y b) las evaluaciones a gran escala como una contingencia de la realidad educativa vigente. Como conclusión, se asume que el contexto histórico de los años 1980 representó, por un lado, la sustentación ideológica para las evaluaciones mencionadas y, por otro lado, promovió la justificación social para los emergentes mecanismos de evaluación a gran escala.

Palabras clave: evaluación a gran escala; política educativa; contexto de los años 1980.

Abstract: Currently, large-scale evaluations are one of the most effective actions in defining the directions of education in Brazil. But what is the historical scenario of large-scale evaluations and what are the implications of such a scenario for strengthening these assessments? How did such action become a political guideline nowadays? Based on a bibliographical research based on an analyticalreconstructive methodology, the text assumes that large-scale evaluations emerge as dated and historical phenomena especially from the 1980s. In this sense, the objective is to discuss historically and historically the 1980s as a preparation scenario for the reforms of the 1990s, which also included the emergence of large-scale evaluations, tied to two positions: a) large-scale evaluations as an international agenda that materialized, in the field of educational policies, an ideological tendency referenced and strengthened in the installation and expansion of the evaluating State, and b) largescale assessments as a contingency of current educational reality. As a conclusion, it is assumed that the historical context of the 1980s represented, on the one hand, the ideological support for the aforementioned evaluations and, on the other hand, promoted the social justification for the emerging mechanisms of large-scale evaluation.

Keywords: large-scale evaluation; educational policy; context of the 1980s.

SUMARIO: 1. Reconstituindo a história das avaliações em larga escala no Brasil. 2. O Estado Avaliador, tendências e agendas internacionais. 3. A necessidade de avaliar... 4. Conclusões provisórias... 5. Referências.

Quem viveu, sabe... quem pesquisa, tem alguma ideia! Os anos 80 do século $x x$ foram emblemáticos e inesquecíveis para o Brasil. No campo social, político, cultural e científico os acontecimentos se aceleraram de forma abrupta. Tomados pela ânsia de olhar para frente e enterrar o passado, os anos 1980 tornaram-se um momento/monumento de passagem entre o velho e o novo. Um pacto com o futuro e a esperança de que as promessas da modernidade fossem finalmente cumpridas, banhou toda a década.

No Brasil a abertura política; um desenho de democracia no ar; os movimentos sociais; o rock nacional; a liberdade de expressão e, ao final daquela década, a constituinte e as eleições presidenciais, só para lembrar alguns sinais deste período, materializaram a crença generalizada de que o futuro seria melhor. Os anos 1980 trouxeram a expectativa de enterrar a carrancuda década de 1970, com suas guerras, incertezas e ditaduras. 
Estes anos de transições e promessas fáceis também formaram o cenário para o surgimento e fortalecimento de um novo tipo de Estado: o Estado Avaliador. Sai de cena o estado ditatorial, mas deixa em seu lugar um estado também controlador, performático e alinhado com os princípios do neoliberalismo que, após breves acenos de outras opções político-econômicas acabou, ao final de década de 1980, por se firmar como o princípio hegemônico.

Neste contexto são fortalecidos os debates sobre o sistema nacional de avaliação da educação básica, assim como os primeiros ensaios, no cenário educacional, da avaliação de sistemas, também identificada como avaliação externa ou em larga escala, que "refere-se à aferição padronizada do rendimento escolar dos alunos, realizada no âmbito do sistema nacional ou dos sistemas estaduais de avaliação do ensino básico» (Barreto et al., 2001, p. 51).

A avaliação em larga escala caracteriza-se por ser externa a rede de ensino, sistema educacional ou unidade educativa a qual se destina, pautando-se em testes padronizados/uniformizados, aplicados a uma população de grande porte (séries/ anos escolares ou etapas de conclusão de escolarização), além de ser baseada na teoria de resposta ao item.

Os objetivos da avaliação em larga escala do sistema escolar [...], são os de informar o que populações e subpopulações de alunos em diferentes séries sabem e são capazes de fazer, em um determinado momento, e acompanhar sua evolução ao longo dos anos. Não é seu objetivo fornecer informações sobre alunos ou escolas individuais (Klein \& Fontanive, 1995, p. 30).

Banhados pela ideia de que contextos históricos e ações de políticas educacionais não são passíveis de separação, sustentamos a crença que os movimentos de avaliação educacional são/estão diretamente vinculados aos contextos históricos e situacionais que lhes servem de ancoradouro. Nessa direção, os anos 1980 foram decisivos para a constituição da avaliação em larga escala no cenário educacional, posto que...

...as perspectivas economicista e tecnicista no tratamento da questão da avaliação educacional, ao lado do questionamento acadêmico e social da qualidade do ensino e da reivindicação de descentralização, concorreram para que, no início dos anos 80 , fossem iniciadas, pelo Estado, as experiências de avaliação em larga escala e, ao final da década, fosse implantado um sistema nacional de avaliação, com vistas à modernização do setor educacional (Coelho, 2008, p. 232).

Assim, o texto objetiva discutir circunstancial e historicamente os anos 1980 como cenário de preparação para as reformas dos anos 1990 que incluíram também o surgimento das avaliações em larga escala, tangenciando dois posicionamentos: 
a) as avaliações em larga escala como agenda internacional que materializaram, no campo das políticas educacionais, uma tendência ideológica que faz parte da instalação e fortalecimento do Estado avaliador, e b) as avaliações em larga escala como uma contingência da realidade educacional vigente.

Para cumprir seu objetivo, a pesquisa que deu origem ao texto em tela foi realizada prioritariamente em base bibliográfica (revisão temática), pautada por uma metodologia analítico-reconstrutiva firmada através da roteirização de dados sobre a história das avaliações em larga escala no Brasil, principalmente sobre o protagonismo dos anos 1980 nessa história.

Para a revisão temática, foi selecionado um conjunto de textos acadêmicos que abordam a gênese das avaliações em larga escala no contexto brasileiro dos anos 1980, inserindo a pesquisa na perspectiva do 'Estado do Conhecimento' (Morosini \& Fernandes, 2014), compreendido como um inventário sobre determinado aspecto ou pauta da produção acadêmica, visando catalogar «tendências, ênfases, escoIhas metodológicas e teóricas, aproximando ou diferenciando trabalhos entre si, na escrita de uma história de uma determinada área do conhecimento» (Ferreira, 2002, p. 265).

Os textos selecionados compreendem desde textos clássicos, como Pestana, 1992; Gomes Neto \& Rosenberg, 1995; Pestana, 1999; Fontanive \& Klein, 2000; Barretto et. all, 2001; Souza \& Oliveira, 2003, bem como textos oriundos de estudos mais contemporâneos, como Dametto \& Esquinsani, 2015; Bauer, Alaverse, \& Oliveira, 2015; Zatti \& Minhoto, 2019; Bauer, 2019, em uma revisão seguramente não esgotada pelos limites do texto em tela.

\section{RECONSTITUINDO A HISTÓRIA DAS AVALIAÇÕES EM LARGA ESCALA NO BRASIL}

Um razoável número de conquistas sociais e avanços democráticos se consubstanciaram no Brasil na década de 1980, em grande medida conduzidas por uma inequívoca mobilização social tracejada, sobretudo, pela luta contra o pesado fardo dos anos ditatoriais...

A busca pela redemocratização do país, à vista da brutal desigualdade na redistribuição da renda, à vista de um desenho pouco animador do pacto federativo, conduziu a uma impressionante mobilização popular. Renascem os sonhos, sobem as expectativas, desenha-se a vontade de uma realidade mais promissora, mais democrática e mais justa (Cury, 2008, p. 216).

Esta mobilização tem seu ápice na Constituição de 1988 que sustenta, «na proclamação de direitos da cidadania, na assinalação de novas obrigações do Estado, a 
vontade de fazer, no país, [...] um acerto de contas com a modernidade, expurgando do passado um enorme passivo com a justiça e com a democracia» (Cury, 2008, p. 216). E este acerto de contas restou por legitimar, entre outros movimentos, o processo de amplo acesso de camadas populacionais aos bancos escolares, que já vinha crescendo substancialmente.

Porém o dilatado acesso aos bancos escolares - configurando a escolarização de massas -, fez vigorar o debate sobre a qualidade ofertada nas escolas que acoIhiam a estas camadas populacionais, sendo que na década de 1980

[...] chegam ao auge as discussões sobre os vários problemas que ocorriam nos sistemas educacionais, apontados pelos pesquisadores da área de educação. Com o debate público sobre indicadores que mostravam o alto índice de fracasso escolar no país (altos índices de repetência e de evasão escolar; baixos índices de conclusão), uma das questões que se colocava é que não se possuíam dados sobre o desempenho escolar efetivo dos alunos em nível de sistema e os fatores a ele associados (Gatti, 2014, p. 16).

O debate sobre a ausência de dados e indicadores que pudessem endereçar as proposições de políticas para a área da educação, restou por incorporar ao conceito geral um importante sinônimo: a avaliação.

Surge portanto, no Brasil, o emparelhamento entre avaliação e controle sobre a qualidade da educação ofertada, que pautou um conjunto de ações políticas e de gestão educacional deflagrados a partir de 1980, especialmente a partir de 1982, com a vigência do IV Acordo MEC/BIRD, que indicava o desenvolvimento de um sistema de avaliação da educação. Neste momento são realizados...

...os primeiros estudos com o objetivo de se estabelecer um sistema de avaliação ocorreram dentro do Programa de Educação Básica para o Nordeste Brasileiro EDURURAL. O programa foi lançado em 1980 e previa um investimento de US\$ 91,4 milhões, sendo que $35 \%$ do total eram oriundos de um empréstimo solicitado ao Banco Mundial. Tinha por objetivo expandir o acesso à escola primária, diminuir as taxas de repetência e evasão e melhorar o rendimento escolar dos alunos. Foi implantado em mais de 400 municípios, escolhidos entre aqueles considerados menos desenvolvidos, no período entre 1981 e 1987 (Horta, 2007, p. 6).

Assim, diante da ausência de dados e o emparelhamento entre avaliação e controle , o processo de organização de indicadores mensuráveis passou ao status de premência onde, nos anos 1980, contou com o envolvimento do INEP - Instituto Nacional de Estudos e Pesquisas Educacionais Anísio Teixeira, iniciando «um programa de avaliação do rendimento escolar de alunos de 10 e $2 \circ$ graus. Começou com uma amostra de escolas de 1 o grau da rede pública de 69 cidades de vários estados e fez, depois, outras avaliações, envolvendo mais 29 cidades» (Barretto et al., 2001, p. 68). 
Como etapa importante dos movimentos registrados no período, o MEC organizou, em 1987, a proposição de «uma avaliação de rendimento escolar em 10 capitais de estados do país, para se aquilatar se um processo de avaliação mais amplo por parte do Ministério seria viável e traria resultados relevantes (Gatti, 2014, p.17).

Em 1988 há, ainda, outros ensaios de avaliações em larga escala na educação básica brasileira. De acordo com Werle, naquele ano o MEC...

...realiza uma aplicação piloto nos estados do Paraná e Rio Grande do Norte. Ora, duas eram as forças impelindo a educação no sentido de fortalecer os procedimentos de avaliação. Por um lado, o Banco Mundial demandava a análise de impacto do Projeto Nordeste realizado no âmbito do acordo MEC/BIRD e, por outro, o MEC tinha interesse em realizar uma avaliação mais ampla do ensino público (Werle, 2014, p. 163-164).

Como resultado concreto "estes primeiros estudos mais abrangentes de alunos e escolas serviram de base para a implantação do SAEB - Sistema de Avaliação da Educação Brasileira» (Gatti, 2014, p. 18). Além do mais, o desenvolvimento do Sistema Nacional de Avaliação da Educação Básica - SAEB...

...foi objeto de um convênio firmado entre a SENEB e o IICA- Instituto Interamericano de Cooperação para a Agricultura, da OEA. O projeto foi montado para avaliar o Projeto Nordeste, um acordo de empréstimo que vinha sendo negociado com o Banco Mundial. Como a proposta de avalição era muito abrangente houve decisão da SENEB de realizar o estudo no Brasil inteiro. Assim, naquele ano de 1988, uma equipe da SENEB, com o apoio do IICA, a cooperação e a consultoria do Professor Júlio Jacobo e outros, desenvolveu a metodologia de avaliação que, por meio de um levantamento de dados, permitiria atingir dois objetivos: Primeiramente, o de buscar qualificar os resultados que o sistema educacional vem obtendo e, com isto, tornando mais claros estes resultados, evidenciar o desempenho da escola pública no Brasil, já que, na primeira aplicação do Sistema, foram realizados levantamentos apenas em escolas públicas de 10. grau, das redes estadual e municipal. O segundo objetivo era criar e consolidar competências, em todos os estados brasileiros, para tratar de questões relacionadas à avaliação do sistema educacional. Trata-se, portanto, de um sistema baseado na existência e funcionamento de equipes do MEC e das secretarias estaduais de educação (Pestana, 1992, p 81-82).

Esses movimentos e ações em torno do acompanhamento mais objetivo do desempenho de redes e sistemas de ensino fez emergir um sistema próprio de monitoramento, capitaneado pela avaliação como ação e indicador capaz de, em um primeiro momento, pronunciar diagnósticos acerca da educação nacional. Justo por isso, 
...nos anos finais da década de 1980 registra-se a primeira iniciativa de organização de uma sistemática de avaliação do ensino fundamental e médio, em âmbito nacional. Esta sistemática é denominada pelo Mec, a partir de 1991, de Sistema Nacional de Avaliação da Educação Básica (SAEB). O SAEB toma como um dos indicadores da avaliação o desempenho em provas de uma amostra de alunos do ensino fundamental e médio, de todas as Unidades Federadas (Souza; Oliveira, 2003, p. 880).

Mais tarde, em 2005, o SAEB foi modificado em sua configuração original, sendo dividido em dois instrumentos distintos: a Avaliação Nacional da Educação Básica - ANEB - e a Prova Brasil. Entretanto, os roteiros traçados pelo Sistema em implementação no final da década de 1980, somaram-se a tendências e movimentos internacionais, sendo que já na década seguinte, nos anos $1990 .$.

...em praticamente quase todos os países da América Latina, são criados sistemas nacionais de avaliação da aprendizagem. Este movimento que começa nos Estados Unidos em fins da década dos 60, se expande para a Europa na década dos 70 e nos anos 80 atinge a Ásia e a Oceania (Horta, 2007, p. 5).

Assim, as ações de políticas educacionais no Brasil inserem-se de maneira orgânica em um contexto próprio dos anos 1980, desvelando o momento histórico como palco/cenário para o movimento de gestão educacional e monitoramento da qualidade amparado em avaliações de larga escala.

\section{O ESTADO AVALIADOR, TENDÊNCIAS E AGENDAS INTERNACIONAIS}

O contexto dos anos 1980 apresentou também, o fortalecimento das agendas internacionais na condução do debate pedagógico e político no campo educacional.

Já no início da década de 80, o MEC começou a incentivar a produção de estudos sobre avaliação do rendimento escolar, estimulado, principalmente, pelas discussões com agências internacionais. Em quase todos os últimos acordos assinados com o Banco Mundial, está presente um componente de avaliação educacional, visando verificar a efetividade das ações geradas pelo acordo (Gomes Neto \& Rosemberg, 1995, p. 16).

Tais agendas internacionais - construídas ao longo das últimas décadas -, convergiam para avaliações de desempenho dos sistemas educacionais. Desta feita, os movimentos iniciais de avaliação educacional no Brasil estão associados aos movimentos do contexto internacional: 
[...] Constituem parte desse contexto de influência, a aprovação do Primary and Secondary Education Act, em 1965, nos Estados Unidos e a publicação do Informe Coleman em 1968, que se conjugam com a criação da Internacional Association for the Evaluation of Educacional Achievement - IEA, que se propõe a promover e realizar estudos internacionais de avaliação educacional, e ainda com a experiência de construção, nos anos de 1970, de indicadores internacionais de qualidade da educação pela Organização para a Cooperação e Desenvolvimento Econômico - OCDE (Coelho, 2008, p. 233).

Esse contexto internacional fomenta e aprofunda um movimento partícipe do corolário neoliberal, onde, "a partir da década de oitenta, o interesse demonstrado pela avaliação, sobretudo por parte de governos neoconservadores e neoliberais, começou a ser traduzido pela expressão 'Estado Avaliador'» (Afonso, 2009, p. 49). Desta feita, a implementação de políticas e controle da ação docente, reflete o cenário contextual dos anos 1980, informados por novos modelos em relação a gestão educacional, assoalhando a perspectiva do Estado-avaliador. Assim,

Desde a década de 1980, a reestruturação do Estado tornou-se tema central no debate político em diversos países, originando políticas que alteraram a estrutura da administração pública, inclusive na Educação. Essas reformas caracterizaram-se pela adoção de uma série de estratégias presentes no setor privado e de dispositivos de mercado, a exemplo da avaliação de desempenho dos agentes, de políticas de accountability e responsabilização, da valorização da performance dos sistemas e modificação dos modos de regulação típicos do poder público sobre a educação. O fundamento das reformas foi a suposta necessidade de modernizar o legado ineficiente da administração pública burocrática, tendo como propósito superar formas tradicionais de gestão para garantir maior eficiência e eficácia dos serviços educacionais, implementando uma nova organização dos sistemas (Zatti \& Minhoto, 2019, p. 02).

O Estado avaliador pode ser conceituado, em amplos traços, como o Estado que adota «um ethos competitivo, neodarwinista, passando a admitir a lógica do mercado, através da importação para o domínio público de modelos de gestão privada, com ênfase nos resultados ou produtos dos sistemas educativos» (Afonso, 2009, p. 49).

A denominação dessa nova lógica como Estado-avaliador aponta para a «transição de uma forma de regulação burocrática e fortemente centralizada para uma forma de regulação híbrida que conjuga o controlo pelo Estado com estratégias de autonomia e autorregulação das instituições educativas» (Afonso, 2001, p. 25), onde a liberdade da unidade escolar é controlada pela verificação externa, em um jogo de co-responsabilizações definidas pelo estado. 
Partindo de tal conceito, o Estado avaliador legitima o controle social sobre o trabalho docente (aferição de resultados), sendo que...

de certa forma, pode-se dizer que, valendo-se de argumentos que atraem o interesse público pelos seus apelos democráticos, esse tipo de Estado exerce sua função com a adesão de grandes setores da população. A emergência e o desenvolvimento do Estado avaliador são justificados e legitimados como uma importante maneira de tornar transparente para o público a forma como as instituições atuam e utilizam os recursos públicos (Santos, 2004, pp. 1151-1152).

Este modelo de Estado é pautado pela racionalidade financeira e produtividade, onde «[...] a ordem é reduzir o insucesso para alcançar menos desperdício de recursos humanos e materiais» (Shiroma et al. 2002, p. 13), auto legitimando-se através de práticas pretensamente transparentes, consolidando a política de avaliações em larga escala, onde o emprego do dinheiro público é traduzido em serviços educacionais e resultados mensuráveis. No contexto do Estado avaliador, "a fé em indicadores mensuráveis passa a ser o exemplo paradigmático das mudanças neoliberais e neoconservadoras" (Afonso, 2009, p. 50).

Com este pano de fundo, a emergência da regulação avaliativa no campo da educação influenciou no percurso da configuração de um novo modelo de gestão: as avaliações em larga escala como subsídios para ações e políticas educacionais (tripé avaliação - informação - ação). Assim,

mudanças no papel do Estado que se configuraram a partir dos anos 1980 e que têm, como forte característica, o enfraquecimento do Estado de Bem-estar Social e a tendência de se descentralizar a oferta de serviços sociais sem, no entanto, que o Estado perca o controle sobre tal oferta. Nessa conjuntura [...] a avaliação de redes de ensino passa a ser um ponto de destaque nas propostas de políticas públicas em vários países que se veem obrigados a racionalizar a aplicação dos recursos disponíveis, descentralizar o gerenciamento do sistema educacional e, ao mesmo tempo, controlálo (Bauer, 2019, pp. 15-16).

Desta sorte, as avaliações externas restaram por apresentar (e representar) a via de regulação estatal da educação, consolidando o estado avaliador e perpetrando a 'cultura do desempenho' (Santos, 2004, p. 1151), tão referenciada contemporaneamente.

De outra forma, as avaliações em larga escala representam o Estado Avaliador na medida em que

... expressam, no limite, uma concepção acerca do papel do Estado na condução das políticas educacionais. Ao que parece, a questão central nesta proposta não é a 
de buscar subsídios para intervenções mais precisas e consistentes do poder público, ou seja, uma análise das informações coletadas para definição e implementação de políticas para a educação básica, mas sim difundir, nos sistemas escolares, uma dada concepção de avaliação, que tem como finalidade a instalação de mecanismos que estimulem a competição entre as escolas, responsabilizando-as, em última instância, pelo sucesso ou fracasso escolar (Souza \& Oliveira, 2003, p. 881).

O fenômeno das avaliações em larga escala, superada a novidade inicial e já sob o olhar suspeitoso de toda uma corrente de intelectuais, nasceu e vigorou nos anos 1980 também como uma tendência ideológica, como parte das estratégias de instalação e fortalecimento do neoliberalismo.

Apesar dessa suspeição, as avaliações em larga escala prosperaram como discurso e prática agregada ao controle de mercado (oferta/procura; cliente/serviço; custo/benefício...), na medida em que

a avaliação legitima "valorações» úteis à indução de procedimentos competitivos entre escolas e sistemas para melhorar pontuações nos rankings, definidos basicamente pelos desempenhos em instrumentos de avaliação em larga escala. Tal competição é garantida pela associação entre desempenho e financiamento, podendo redundar em critérios para alocação de recursos, que incidem, até mesmo, em remunerações diferenciadas dentro de sistemas de ensino que até há pouco trabalhavam com a noção de remunerações isonômicas... (Souza \& Oliveira, 2003, p. 876).

Tal instrumento de política e gestão/controle educacional, mesmo criticado, estabeleceu a cultura do desempenho e engendrou uma suposta face de necessidade,

Uma avaliação do sistema de ensino que tem como referência de desempenho tais indicadores estandardizados termina por não permitir formas mais flexíveis e diferenciadas de trabalho pedagógico. Neste sentido, aquilo que não for possível de ser mensurado e diretamente observável deixa de ter importância para esse tipo de avaliação. Paradoxalmente, a proposta de tornar transparente o desempenho das pessoas e das instituições termina por obscurecer, ao invés de revelar, aspectos importantes do que ocorre no cotidiano das escolas. Na cultura do desempenho constantemente tanto a agenda do professor como a do aluno, no que diz respeito ao processo ensinoaprendizagem, tem que ser abandonadas em função daquilo que foi definido pelas autoridades educacionais como indicadores de bom desempenho (Santos, 2004, p. 153).

Avaliar e apontar lacunas foram atitudes promovidas à centralidade nos processos pedagógicos, como se fosse necessário mostrar - numérica e quantitativamente -, a medida exata do quão os 'erros' dos 'outros' haviam sido perniciosos para a qualidade da educação. 
Ao gosto do neoliberalismo, a tendência de comparar, conferir, medir, regular, rankear acabou por promover uma pressão/cobrança externa sobre as escolas que, em geral, não corresponde a pressão por democracia no interior das mesmas, ou sequer pela melhoria das relações entre os membros da comunidade educativa ou das condições de trabalho docente. A lógica é competir, instaurar comparações e adotar medidas externas de correção de resultados.

\section{A NECESSIDADE DE AVALIAR...}

Quer por suas múltiplas dimensões e abrangência, quer pela inserção de seus pressupostos em todas as atividades, a avaliação poderia, sem qualquer susto de ordem epistemológica, figurar no panteão das necessidades básicas humanas. Vivemos sob o imperativo constante de avaliar situações, pessoas, contextos. Avaliamos a todo o instante e, seguramente, "desde o início do processo civilizatório houve alguma forma de avaliação. Ousaríamos dizer que a avaliação surgiu com o próprio homem» (Vianna, 2000, p. 22).

Avaliamos, também, pelos mais diferentes motivos mas, em geral, a razão mais forte que nos leva ao ato de avaliar reside na necessidade de medir, verificar, averiguar, produzir informações que possibilitem o controle sobre determinada situação. Na educação, o ato de avaliar está ligado três níveis: «avaliação em larga escala em redes de ensino; avaliação institucional da escola e a avaliação da aprendizagem em sala de aula, sob responsabilidade do professor». (Freitas, 2009, p.10).

A avaliação em larga escala é, portanto, um nível de avaliação no campo educacional. E se é necessário procurar respostas para a qualidade educacional, essas respostas devem ser fornecidas....

Se a qualidade na educação é um fenômeno complexo que possui determinações intraescolares (currículo, formação docente, gestão escolar, avaliação da aprendizagem, condições de trabalho, infraestrutura das escolas etc.) e extraescolares (condições de vida da população, capital econômico, cultural e social das famílias dos alunos, entorno social da escola, distribuição de renda, violência, entre outros), o aumento do desempenho dos alunos nos exames é parte importante desse fenômeno, ainda que este não se esgote naquele, pois a medição da aprendizagem permite o aprofundamento do diagnóstico da situação da educação brasileira e o delineamento de iniciativas de políticas educacionais nesse terreno (Alaverse; Bravo \& Machado, 2013, p. 26).

Nesta direção, as avaliações em larga escala restaram por representar uma forma de constatar, averiguar, apontar a situação da educação nacional - sobretudo a educação ofertada em escolas públicas -, amealhando indicadores que servissem como base para a consecução do binômio acesso/sucesso. As avaliações em larga escala formam-se como uma contingência da realidade educacional vigente. 
Entretanto mesmo contingenciais, as avaliações em larga escala não perdem o seu caráter de controle e poder

É inevitável percebermos que tais procedimentos, com olhares voltados ao já realizado, desenham a ordem futura da coisa avaliada. Os relatórios finais de uma avaliação, bem como os próprios procedimentos desta, implícita ou explicitamente, conformam as ações políticas sobre a realidade da qual se ocupam. Dentro desta perspectiva, tomam-se as avaliações, acima de tudo, como ferramentas de poder, capazes de coagir, de modo ostensivo ou velado, os sujeitos envolvidos no processo educacional e, em consequência, traçar o destino do trabalho realizado nas instituições as quais eles pertencem (Dametto \& Esquinsani, 2015, p. 620).

Freitas pondera que a avaliação em larga escala «é um instrumento de acompanhamento global de redes de ensino com o objetivo de traçar séries históricas do desempenho dos sistemas, que permitam verificar tendências ao longo do tempo, com a finalidade de reorientar políticas públicas» (2009, p. 47).

Além do mais,

os diferentes e reiterados tipos de críticas aos chamados 'ineficientes sistemas burocráticos de governo' deram abertura e legitimidade à penetração crescente de uma nova lógica de administração derivada do setor privado. Essa nova lógica lentamente vai introduzindo formas, muitas vezes bastante sutis, de privatização, mas seu elemento-chave é a análise de desempenho de pessoas e de instituições. A garantia da implementação de políticas, que se estruturam e se desenvolvem com base na cultura do desempenho, é assegurada pela criação do Estado avaliador (Santos, 2004, p. 1151).

Por outro lado, as amiudadas críticas aos professores em geral legitimaram, ante a opinião pública, a aplicação de avaliações de larga escala como forma de controle estatal do trabalho pedagógico, fruto de uma nova lógica de administração derivada do setor privado. De certa forma, as 'falhas' justificaram o discurso da qualidade via aferição do desempenho.

\section{CONCLUSÕES PROVISÓRIAS...}

Sob o amparo da revisão de literatura efetuada no artigo em tela, é lícito afirmar que a década de 1980 foi a gênese de ações de avaliação em larga escala que foram, posteriormente e sob a bandeira do Estado Avaliador, ampliadas e solidificadas nas décadas posteriores. Assim, a ação política de avaliar redes e sistemas de ensino, de forma padronizada e através de instrumentos de aferição em larga escala tem, aqui no Brasil, mais de 30 anos. 
A década de 1980 vivifica a prática de avaliações externas ou em larga escala, descolando o foco do processo avaliativo do âmbito privado e personalizado da sala de aula e lançando sua discussão para unidades escolares, redes e sistemas de ensino. Desta feita, as avaliações externas ou em larga escala se constituem «num dos traços do conjunto das reformas educacionais implementadas desde a década de 1980» (Alaverse; Bravo \& Machado, 2013, p. 16).

Contemporaneamente, a agenda de debates acerca da educação nacional tem sido pautada, em grande medida, pela ampla divulgação das avaliações externas realizadas em redes e sistemas de ensino, sobretudo porque as avaliações em larga escala restam por conduzir de forma protagonista o debate acerca da educação, partir do abastecimento de informações - resultados, rankings, comparações... que podem ser analisadas por toda ordem de teorias e estatísticas.

Os anos 1980 figuram, seguramente, como gênese contextual e histórica das avaliações em larga escala, a partir do encontro entre dois posicionamentos: a) as avaliações em larga escala como agenda internacional que materializaram, no campo das políticas educacionais, uma tendência ideológica referenciada e fortalecida na instalação e ampliação do Estado avaliador, e b) as avaliações em larga escala como uma contingência da realidade educacional vigente.

De tal modo, assume-se que o contexto histórico dos anos 1980 representou, por um lado, a sustentação ideológica para as avaliações referidas e, por outro lado, promoveu a justificativa social para os emergentes mecanismos de avaliação em larga escala.

\section{REFERÊNCIAS}

Alavarse, O., Bravo, M. H., \& Machado, C. (2013). Avaliações externas e qualidade na educação básica: articulações e tendências. Estudos em Avaliação Educacional, 24(54), pp. 12-31.

Afonso, A. J. (2009). Avaliação educacional: regulação ou emancipação? Para uma sociologia das políticas avaliativas contemporâneas. 4. a ed. São Paulo: Cortez.

Afonso, A. J. (2001). Reforma do Estado e Políticas Educacionais: entre a Crise do Estado-Nação e a Emergência da Regulação Supranacional. Educação \& Sociedade, ano 22, n.o 75, pp. 15-32.<www.scielo.br/pdf/es/v22n75/22n75a03. pdf>.

Barretto, E. S. de S., Pinto, R. P., Martins, A. M., \& Duran, M. C. G. (2001). Avaliação na educação básica nos 90 segundo os periódicos acadêmicos. 
Cadernos de Pesquisa, 114, pp. 49-88. <https://dx.doi.org/10.1590/S0100$15742001000300003>$.

Bauer, A., Alavarse, O. M., \& Oliveira, R. P. de. (2015). Avaliações em larga escala: uma sistematização do debate. Educação e Pesquisa, 41(spe), pp. 1367-1384. <https://dx.doi.org/10.1590/S1517-9702201508144607>.

Bauer, A. (2019). Avaliação de Redes de Ensino e Gestão Educacional: aportesteóricos. Educação \& Realidade, 44(1), e77006. <http://dx.doi.org/10.1590/2175623677006>.

Coelho, M. I. de M. (2008). Vinte anos de avaliação da educação básica no Brasil: aprendizagens e desafios. Ensaio: Avaliação e Políticas Públicas em Educação, 16(59), pp. 229-258. <https://dx.doi.org/10.1590/S010440362008000200005>.

Cury, C. R. J. (2008). A educação escolar, a exclusão e seus destinatários. Educação em Revista, 48, pp. 205-222. <https://dx.doi.org/10.1590/S010246982008000200010>.

Dametto, J.; Esquinsani, R. S. S. (2015) Avaliação educacional em larga escala: performatividade e perversão da experiência educacional. Educação, 4(3), pp. 619-630, set. <http://dx.doi.org/10.5902/1984644413742>.

Ferreira, N. S. de A. (2002). As pesquisas denominadas «estado da arte». Educação \& Sociedade, 23(79), pp. 257-272. <https://dx.doi.org/10.1590/S0101$73302002000300013>$.

Fontanive, N. S. \& Klein, R. (2000). Uma visão sobre o Sistema de Avaliação da Educação Básica do Brasil - Saeb. Ensaio, 8(29), pp. 409-439.

Freitas, L. C. (2009) Avaliação educacional: caminhando pela contramão. Rio de Janeiro: Vozes.

Gatti, B. A. (2014). Avaliação: contexto, história e perspectivas. Olh@res, 2(1), pp. 08-26.

Gomes Neto, J. B. \& Rosenberg, L. (1995). Indicadores de qualidade do ensino e seu papel no Sistema Nacional de Avaliação. Em Aberto, 15(66), pp. 13-28. 
Horta, J. L. (2007). Um olhar retrospectivo sobre a avaliação externa no Brasil: das primeiras medições em educação até o SAEB de 2005. Revista Iberoamericana de Educación, 42(5), pp. 1-13

Morosini, M. C. \& Fernandes, C. M. B. (2014). Estado do Conhecimento: conceitos, finalidades e interlocuções. Educação Por Escrito, 5(2), pp. 154-164.

Pestana, M. I. G. de S. (1992). O Sistema Nacional de Avaliação da Educação Básica. Estudos em Avaliação Educacional, 05(01), pp. 81-83.

Pestana, M. I. G. de S. (1999). O sistema de avaliação brasileiro. Revista Brasileira de Estudos Pedagógicos, 79(191), pp. 65-73.

Souza, S. Z. L. de \& Oliveira, R. P. de. (2003). Políticas de avaliação da educação e quase mercado no Brasil. Educação \& Sociedade, 24(84), pp. 873-895. <https:// dx.doi.org/10.1590/S0101-73302003000300007>.

Vianna, H. M. (2000) Avaliação Educacional. São Paulo: IBRASA, 2000.

Werle, F. O. C. (2014). Panorama das políticas públicas na educação brasileira: uma análise das avaliações externas de sistemas de ensino. Revista Lusófona de Educação, 27(27), pp. 159-179.

Zatti, A. M. \& Minhoto, M. A. P. (2019). Política de avaliação do desempenho docente nas redes estaduais de ensino do Brasil. Educação e Pesquisa, 45, e188993. Epub 28 de feveiro de 2019. <https://dx.doi.org/10.1590/s16784634201945188993>. 